Причины конфликтных отношений в диаде «подросток-родитель» у школьников с разным уровнем интеллектуального развития

DOI 10.20323/978-5-00089-474-3-2021-83-92

Аннотация.В содержании статьи представлены результаты выявления причин конфликтов между умственно отсталыми подростками и их родителями в сравнении с нормально развивающимися сверстниками. Предмет исследования зависит от уровня интеллектуального развития школьника, от возраста подростка (младший, средний, старший), структуры семьи (полная, неполная), пола, стратегий и форм поведения в конфликте подростка и родителя.

Ключевые слова: конфликтные отношения, причины конфликтного поведения, стратегии и формы поведения в конфликте, подростки с интеллектуальными нарушениями, родители.

\title{
N.V. Zaigraeva
}

The reasons for conflict relations in the dyad "teenager-parent" in schoolchildren with different levels of intellectual development

Abstract. The content of the article presents the results of identifying the causes of conflicts between mentally retarded adolescents and their parents compared to normally developing peers. The subject of the study depends on the level of intellectual development of a school student, on the age of the teenager (junior, middle, senior), on the family structure (full, incomplete), on the gender, on the strategies and forms of behavior in the conflict between the teenager and the parent.

Keywords: conflict relations, causes of conflict behavior, strategies and forms of behavior in conflict, adolescents with intellectual disabilities, parents.

В процессе воспитания детей родители неизбежно сталкиваются с трудностями. Подростковый возраст считается наиболее сложным и противоречивым, ребенок перестраивается как личность, пересматривает отношение не только к себе, но и к другим. Основным диагностическим признаком этого возраста является конфликтное поведение в семье. Вступление во взрослую жизнь происходит тяжело, и в это время отношения с родителями переходят на качественно новый этап развития. Подросток начинает сопротивляться воспитательным

(C) Заиграева Н.В., 2021 
воздействиям взрослых, конфликтовать с ними, обособляется, возникают трудности общения. В поведении появляются непослушание, грубость, жестокость, агрессивность.

Данная проблема - причины конфликтных отношений в диаде «умственно отсталый подросток - родитель» представляет для нас интерес, поскольку она является недостаточно разработанной в специальной психологии.Имеется ряд исследований о выявленных причинах конфликтных отношений в семьях с нормально развивающимися подростками (Н.В. Заиграева, Н.Ю. Синягина, В.Н. Соколова, О.В. Удова, В.Б. Тарабаева, А.Л. Цветкова и др.). Подобной информации относительно умственно отсталых подростков и их родителей недостаточно (Е.С. Гринина). В связи с этим мы решили выявить и сопоставить причины конфликтного поведения подростков с разным уровнем интеллектуального развития.

Цель настоящего исследования заключается в выяснении причин возникновения конфликтов между умственно отсталыми подростками в разных возрастных группах и их родителями в сравнении со сверстниками с нормальным интеллектуальным развитием для выявления наиболее проблемных сфер в диаде «подросток - родитель».

Нарушение интеллекта сказывается на качестве межличностных отношений, что обусловлено неадекватностью реакций, неумением и неспособностью глубоко осознать характер своих отношений с окружающими, недостаточной коммуникабельностью. Исходя из этого, мы предположили, что выявленные причины конфликтных отношений между подростком и его родителями будут различаться в зависимости от интеллектуального уровня развития подростка, а также от возраста подростка, пола и структуры семьи.

Обследование обучающихся проводилось студенткой Д.В. Назаровой под нашим руководством в школах города Иркутска. Исследованием было охвачено 168 подростков и 48 родителей за три учебных года. Возрастной диапазон учащихся составил семь лет: 911 - предподростковый и младший подростковый возраст, 12-13 средний подростковый возраст, 14-15 - старший подростковый возраст. Соотношение школьников по полу было равным - по 84 человека.

Целевую группу (далее - ЦГ) составили умственно отсталые подростки, обучающиеся в СКОШ №№ 1, 2, 5. В контрольную 
группу (далее - КГ) включили нормально развивающихся сверстников из МОУ «Средняя общеобразовательная школа №№ 7, 10, 35» города Иркутска. Для решения частной задачи были подобраны подростки из полных и неполных семей, поэтому сравнительный анализ проводили в семьях с разной и одинаковой структурой.

Методами исследования были выбраны беседа, анкетирование, составленный нами вариант методики «Незаконченное предложение». Обработку результатов осуществляли с помощью контентанализа, сравнительного метода, качественного и количественного анализа с определением процентного распределения. Достоверность различий определяли по критерию Фишера.

Беседа проводилась с подростками и состояла из двух блоков. Вопросы первого блока были нацелены на выявление причин возможных конфликтных отношений у подростков с родителями. Второй блок включал вопросы для изучения различий в стратегии и формах поведения родителей и подростков в конфликтной ситуации.

Анкета применялась для родителей испытуемых подростков, которая содержала такие же вопросы, как и в беседе со школьниками с целью сопоставления полученных данных в диаде «родитель - подросток».

Вариант методики «Незаконченное предложение» выполняли подростки для установления восприятия эмоционального отношения родителей к подростку.

Проведенный анализ беседы позволил выделить и сгруппировать пять сфер конфликтных отношений между подростком и родителями:

1. Вопросы учебы и поведение в школе (снижение успеваемости, невыполнение уроков, взаимодействие со сверстниками).

2. Качество выполнения домашних обязанностей.

3. Свободное время (режим дня, встречи и общение со сверстниками).

4. Нравственное и нормативное поведение (правдивость-лживость, ненормативная лексика, обзывание).

5. Деструктивные отношения с сиблингами, сверстниками.

6. Другие (более частные) особенности поведения подростков.

Сравнительно-сопоставительный анализ результатов беседы с подростками ЦГ и КГ показал, что в числе наиболее распространен- 
ных причин возникновения конфликтов с родителями в полных семьях являются вопросы учебы, нормативное поведение, невыполнение школьных и домашних обязанностей. Отмечаем, что в общей выборке подростков ЦГ и КГ (младшая, средняя, старшая) существуют значимые различия в причинах возникновения конфликтных отношений из-за вопросов учебы и поведения в школе, которые возникают чаще в КГ. Родители нормально развивающихся школьников контролируют качество успеваемости и поведения в школе, из-за чего возникает недовольство со стороны подростков.

В ЦГ в 4 раза усиливаются конфликты между родителями и подростками от младшего к старшему возрасту по причине ответственности за выполнение домашних обязанностей.

В ЦГ и КГ вне зависимости от интеллектуального уровня развития нарастают конфликты с родителями по мере взросления подростка (от младшего к старшему) по причине проведения «свободного времени».

Сопоставляя данные подростков и родителей, отмечаем, что они совпадают по выделенным группам причин конфликтного взаимодействия (учеба, домашние обязанности, нормы поведения).

Таким образом, среди выделенных причин конфликтных отношений в диаде «подросток - родитель» наблюдаются сходства и различия в сравниваемых группах. Сходства объединяют первую причину конфликтов - «свободное время» и следующую закономерность: чем старше становится подросток, тем больше конфликты увеличиваются. Вторая причина - «нормативное поведение», которое выражается в том, что чем младше подросток, тем чаще родители обращают внимание на нравственное и нормативное поведение (правдивость лживость, ненормативная лексика, обзывание).

Различия заключаются в том, что конфликты возрастают от младшего подросткового возраста к старшему в ЦГ по причинам невыполнения домашних обязанностей, в КГ - по успехам и поведению в школе.

Рассматривая группы причин конфликтных отношений в зависимости от пола подростков, отмечаем, что в ЦГ и КГ среди девочек с разным умственным развитием показатели конфликтности в зависимости от возрастной динамики меняются. Среди умственно отсталых девочек конфликтные отношения увеличиваются в 3 раза по мере их взросления (от младшего к старшему подростковому возрасту) по при- 
чине «невыполнение или некачественное выполнение домашних обязанностей», а у девочек ЦГ, наоборот, эта причина конфликтных отношений уменьшается в 5 раз от младшего к старшему подростковому возрасту. Таким образом, чем старше становится умственно отсталая девочка, тем выше требования предъявляют родители в вопросах домашних обязанностей (уборка квартиры, мытье посуды, соблюдение порядка на рабочем столе). Полученные результаты подтверждаются данными анкет родителей.

Вторая причина возникновения конфликтных отношений среди родителей и девочек - «проведение свободного времени». Показатели конфликтности увеличиваются в ЦГ в 2 раза, в КГ в 4 раза у девочек от младшего подросткового возраста к старшему. Таким образом, по мере взросления девочек родители чаще контролируют их в вопросах режима дня (как правило, это вечерние гуляния).

Среди мальчиков определяются различия в конфликтных отношениях с родителями при сравнении ЦГ и КГ. Чаще возникают противоречия в КГ по вопросам успеваемости и поведения в школе по сравнению с ЦГ.

В ЦГ от младшего к старшему подростковому возрасту в 6 раз чаще возрастают конфликты по причине «выполнения домашних обязанностей» и в 1,5 раза чаще, чем у сверстников КГ. Родители КГ мальчиков одинаково требовательны на протяжении всего подросткового возраста в вопросах выполнения домашних обязанностей.

Кроме того, определяются различия при сравнении младшего и среднего подросткового возраста ЦГ и КГ. Причинами конфликтов выступает «свободное время» и «нормативное поведение». Родители мальчиков ЦГ, учитывая интеллектуальный дефект, в 2 раза чаще контролируют досуг и место нахождения своих детей по сравнению с родителями сверстников КГ.

Среди других выделенных причин конфликтов мальчиков/девочек и их родителей не зафиксированы достоверные различия в ЦГ и КГ.

Сравнивая мнения подростков и их родителей по вопросу частоты возникновения конфликтов, ссор, «непониманий», несовпадений взглядов на жизнь, отмечаем, что к старшему подростковому возрасту в ЦГ и КГ несколько увеличиваются конфликты с родителями вне зависимости от интеллектуального уровня развития под- 
ростка. В 2 - 4 раза чаще конфликты возникают у подростков с матерями, нежели с отцами. Отец, возможно, устраняется от процесса воспитания и контроля.

Мальчики старшего подросткового возраста ЦГ и КГ указывают, что одинаково часто у них возникают разногласия и непонимание с матерями и отцами. Девочки старшего подросткового возраста ЦГ в 75 \% случаев и КГ в 100 \% случаев конфликтуют с матерями.

Далее рассмотрим причины возникновения конфликтных отношений подростков и их родителей в зависимости от структуры семьи в полных (далее - ПС) и неполных семьях (далее - НС). Анализируя причины возникновения конфликтов, мы зафиксировали некоторые различия по полу. Было обнаружено, что у мальчиков из НС в 2,2 раза чаще возникают деструктивные отношения с сиблингами, сверстниками (драки, ссоры) по сравнению с мальчиками из ПС. Если речь идет о сиблингах, то основным мотивом детских ссор, возможно, является ревность к родителям, причем у детей из неполных семей чувство ревности возрастает. Ссора - это способ лишний раз доказать своё превосходство над братом/сестрой.

Драчливое поведение среди сверстников у воспитывающихся без отцов мальчиков, возможно, есть результат искаженного представления о мужском поведении как агрессивном, грубом и жестоком. Именно через деструктивные формы поведения идёт самоутверждение будущего мужчины.

У девочек из НС по сравнению с другими группами испытуемых обостряются отношения по вопросам выполнения домашних обязанностей. Данный факт интерпретируем как желание одинокой матери разделить домашнюю работу с ребенком: мытье посуды, полов и др. Невыполнение или некачественное выполнение домашних обязанностей вызывает конфликт между матерью и девочкой. Таким образом, в результате беседы о причинах возникновения конфликта между подростком и родителями отмечаем, что в каждом подростковом периоде - младшем, среднем, старшем - выявляются разные сферы конфликтного взаимодействия. Чем младше подросток, тем больше возникает противоречий в вопросах учебы, нормативного поведения, выполнения домашних обязанностей, чем старше подросток, тем чаще возникают конфликты на тему режима дня и свободного времени. В неполных семьях конфликты встречаются чаще. Мальчики конфликтуют с сиблингами, девочки с матерями. 
Второй блок вопросов беседы был направлен на изучение стратегии и форм поведения в конфликте подростка и родителя. Школьников спрашивали: «Как ты обычно себя ведешь, когда бываешь не прав?». При помощи метода контент-анализа были выделены три типичных способа поведения подростка в конфликте:

1) «соперничество и противоборство» - стремление добиться своих интересов в ущерб интересам другого участника конфликта. Подростки используют все доступные им средства, чтобы добиться своего, получить максимум желаемого и утвердиться. Соперничество сопровождается открытой борьбой, даже когда подростки осознают, что бывают неправы. Приведем их высказывания: «матерюсь, психую, нервничаю, топаю ногами, обижаюсь, балуюсь, кривляюсь» и др.;

2) «компромисс» - поведение, основанное на взаимных уступках. Такие действия могут в некоторой степени напоминать сотрудничество, однако при помощи компромисса урегулирование конфликта достигается на более поверхностном уровне, чем при сотрудничестве. Подросток сам идет на компромисс, регулирует разногласия через уступки, например: «прошу прощения, говорю правду, исправляюсь, задумываюсь, грущу, опускаю голову, стараюсь вести себя хорошо» и др.;

3) «избегание» - это тип поведения, при котором характерно как отсутствие стремления к кооперации, так и отсутствие тенденции к достижению собственных целей. Подросток стремится выйти из конфликтной ситуации, не решая ее, не уступая, но и не настаивая на своем, например: «молчу, ухожу в другую комнату, ухожу гулять, ухожу в коридор, веду себя как обычно».

В полных семьях, даже когда подростки неправы, они выбирают разные стратегии поведения в конфликте. Мальчики ЦГ чаще в 1,5 - 3 раза выбирают «противоборство». Их сверстники КГ в 1,5 раза больше называли стратегию «избегание». Во всех других случаях явно выраженной стратегии поведения подростка в конфликте мы не отмечаем.

Существенные различия были выявлены в неполных семьях. Наше внимание привлекла группа девочек из НС как самая конфликтная в отношениях с матерями; умственно отсталые девочки проявляют соперничество и противоборство в 80 \% случаев, девочки с нормальным интеллектуальным уровнем развития - в 50 \% случаев.

Вероятно, у девочек, проживающих в НС, матери испытывают тревожность, связанную с неуверенностью эффективного выполнения 
своей воспитательной функции, и стремятся компенсировать отсутствие отца, нередко проявляют неожиданную жёсткость и более строгие отношения, стараясь быть матерью и отцом одновременно. Девочки всевозможными путями пытаются противостоять матери.

Немаловажными являются данные и об обратной связи в конфликтных отношениях, то есть о том, как ведут себя родители, если произошел конфликт. Были выделены разные формы поведения родителей:

1) «агрессия», «подавление», «унижение»- враждебное поведение, направленное на причинение вреда другим, в некоторых случаях с применением физической силы. Приведем высказывания детей: «злится, ругается, обзывает, психует, орет, бьет, наказывает»;

2) «изоляция и лишение» - обособленное поведение от привычных условий жизни и общения, например, «не разговаривает со мной, обижается и молчит, уходит в другую комнату, не отпускает на улицу, ставит в угол»;

3) «сотрудничество» - поведение, при котором участники ситуации приходят к альтернативе, полностью удовлетворяющей интересы обеих сторон. «Сотрудничество» строится на основе баланса интересов и на признании ценности межличностных отношений, то есть спокойная реакция, уравновешенное поведение, например, «ведет себя нормально, грустит, поцелует, просит прощенья».

В полных семьях родители выбирают разные формы поведения в конфликте. Родители подростков ЦГ и КГ чаще (37-40 \%\%) прибегают к повышению голоса, тем самым оказывая на подростка эмоциональное давление. Четверть родителей (19-24\%) отмечают, что стараются выслушать и понять своего ребенка, при этом разговаривают спокойным тоном. Меньшая часть родителей выбирает неэффективную стратегию поведения в конфликте с подростком начинает спорить, вовлекает в конфликт других родственников, применяет физические меры наказания (ремень).

В НС встречаются единичные случаи, когда родитель выбирает форму поведения «сотрудничество» или «приспособление» к ребенку. Участники конфликта не пользуются системой взаимных уступок. Наверное, не стоит подробно останавливаться на том, что инициатива компромисса и его содержание должны исходить от родителя.

Таким образом, в конфликтных отношениях родители из полных и неполных семей выбирают различные формы поведения по отношению к ребенку: в ПС преобладает «изоляция», «лишение» и 
«сотрудничество» в семьях с одним родителем, наряду с выше перечисленными, доминируют «агрессивные формы поведения».

На основе проведенного исследования можно сделать вывод, что конфликт в диаде «подросток - родитель» представляет собой сложное явление и зависит от многих факторов: от интеллектуального уровня развития школьников, динамики подросткового периода, пола, структуры семьи (полная, неполная). Как у нормально развивающихся, так и у умственно отсталых школьников, одним из основных признаков подросткового возраста является конфликтное поведение.

Практическая значимость исследования заключается в том, что нам удалось выявить группы причин конфликтных отношений между родителями и подростками в зависимости от интеллектуального уровня развития школьников. Мы установили стратегии и формы поведения подростков и родителей во время конфликта. Эти данные должны быть известны педагогам, психологам, родителям. Особые конфликтные отношения продемонстрировали девочки и их матери в неполных семьях вне зависимости от уровня интеллектуального развития. Это может быть ориентиром для коррекционной работы по оптимизации их межличностных отношений.

Полученные материалы исследования могут послужить психологическим обоснованием для дифференцированного подхода в процессе психолого-педагогического сопровождения подростков с психическим недоразвитием, учитывая специфику протекания подросткового возраста у данной категории взрослеющих детей.

\section{Библиографический список}

1. Гринина Е.С. Профилактика конфликтов в межличностных отношениях подростков с интеллектуальным недоразвитием : дис. канд. психол. наук. Москва, 2008. 226 с.

2. Заиграева Н.В. Недостатки конфликтной компетентности депривированных воспитанников кадетского корпуса как проявление нарушений процесса социализации // Сопровождение социализации детей с особыми образовательными потребностями: теория и практика : сборник научных трудов. Иркутск : Издательство ИГУ, 2020. С. $133-140$.

3. Синягина Н.Ю. Психолого-педагогическая коррекция детско-родительских отношений. Москва : Академия, 2001. 267 с.

4. Соколова В.Н. Отцы и дети в меняющемся мире. Москва : Академия, 2001. 320 с. 
5. Сорокина А.И. Конфликтность в поведении детей и подростков. Уфа : СПК, 2014. $173 \mathrm{c.}$

6. Тарабаева В.Б. Исследование причин возникновения конфликтов подростков с родителями // Семейная психология и семейная терапия. 1997. № 1. С. 43-52.

7. Удова О.В. Особенности детско-родительских отношений и методы их изучения. Москва : Просвещение, 2003. 196 с.

8. Цветкова А.Л. Особенности поведения подростков, имеющих установки на конфликт : автореф. дис. ... д-ра психол. наук. Москва, 2011. 26 с.

УДК 376.1

Н.В. Шкляр, О.В. Карынбаева, Т.В. Левкова

Психолого-педагогическое сопровождение семей, воспитывающих детей с ограниченными возможностями здоровья

DOI 10.20323/978-5-00089-474-3-2021-92-97

Аннотация. В статье представлены основные направления деятельности Консультативно-методического центра оказания помощи семьям, воспитывающим детей в возрасте от 0 до 18 лет, в том числе детей с ограниченными возможностями здоровья, созданного в рамках федерального проекта «Поддержка семей, имеющих детей» национального проекта «Образование». Обобщен опыт реализации регионального проекта на территории Еврейской автономной области.

Ключевые слова: психолого-педагогическое сопровождение, семья, дети с ограниченными возможностями здоровья, консультативно-методический центр.

N.V. Shklyar, O.V. Karynbayeva, T.V. Levkova

Psychological and pedagogical support for families raising children with disabilities

Abstract. The article presents the main activities of the Advisory and Methodological Center for Assistance to families raising children aged 0 to 18 years, including children with disabilities, created within the

(С. Шкляр Н.В, Карынбаева О.В., Левкова Т.В., 2021 